\title{
EDITORIAL
}

\section{Excess deaths associated with obesity: cause and effect}

International Journal of Obesity (2006) 30, 1171-1172.

doi:10.1038/sj.ijo.0803313

Recently, we estimated the number of excess deaths associated with different levels of body mass index (BMI) based on data from the National Health and Nutrition Examination Survey (NHANES) program. ${ }^{1}$ Our estimates were adjusted for age, sex, smoking, race-ethnic group and alcohol consumption levels. We thought it important to clarify in our article that any associations of weight with mortality were not necessarily causal but might be due, wholly or in part, to other factors, such as activity, diet, body composition or fat distribution, that were associated both with weight and with mortality. We did not consider body weight or BMI as surrogates for diet or for physical activity. In his commentary, Cundiff ${ }^{2}$ does not disagree with us. Rather he reemphasizes and elaborates on some of these points.

Cundiff's contribution is useful to remind the reader that the biological and social factors relating body weight to health outcomes are not fully delineated. As Cundiff points out, poor diet and physical inactivity, or conversely good diet and physical activity, are not the exclusive province of any one weight level. Improvements in dietary intake and increased physical activity and fitness may reduce risk for chronic disease independently of weight. For example, national survey data from NHANES have shown declines since 1960 in the prevalence of high cholesterol at all BMI levels. ${ }^{3}$ Much of the decline, particularly in the 1970s, is likely to have been due to increased public awareness and to changes in the amount and types of fat in the diet, rather than to any widespread use of cholesterol-lowering drugs. In the 1988-1994 NHANES survey, only 3.5\% of the obese population ages 20-74 years reported use of cholesterollowering medications, yet the prevalence of high cholesterol among both obese and lean declined steadily from 1960 to 1994.

Although diet and physical activity levels have an important role to play in explaining the associations of weight with mortality, other factors, such as smoking cessation and medical care are likely to affect the relation of weight to mortality as well. ${ }^{4,5}$ Data from the NHANES surveys suggest the possibility that the impact of obesity on mortality has diminished somewhat over time. ${ }^{1}$ Mortality rates from ischemic heart disease have declined markedly in the US and elsewhere, a decline that appears to be due both to risk factor reductions and to improvements in medical care. ${ }^{4,5}$ The NHLBI clinical guidelines for the treatment of overweight and obesity note that : 'In overweight patients, control of cardiovascular risk factors deserves equal emphasis [to] weight reduction therapy. Reduction of risk factors will reduce the risk for cardiovascular disease whether or not efforts at weight loss are successful.' (NHLBI ${ }^{6}$, p xi.) Some data, however, suggest there may be poorly understood barriers to medical care for obese women. For example, studies in both the US and in Germany have shown that obese women may delay medical treatment and preventive care. ${ }^{7-11}$ Obese women with breast cancer may receive chemotherapy doses that are inadequate for their body weight and have reduced survival as a result. $^{12-14}$

The examples in the previous paragraph show that in studies of weight and mortality it can be difficult to disentangle all the causal effects. Cundiff's cautions against simple interpretations of complex data are well taken.

KM Flegal
Centers for Disease Control and Prevention, National Center for
Health Statistics, Hyattsville, MD, USA
E-mail: kmf2@cdc.gov

\section{Disclaimer}

The findings and conclusions in this report are those of the author and do not necessarily represent the views of the Centers for Disease Control and Prevention.

\section{References}

1 Flegal KM, Graubard BI, Williamson DF, Gail MH. Excess deaths associated with underweight, overweight, and obesity. JAMA 2005; 293: 1861-1867.

2 Cundiff DK. BMI poor surrogate for diet and exercise in assessing risk of death. Int J Obesity 30: 1173-1175.

3 Gregg EW, Cheng YJ, Cadwell BL, Imperatore G, Williams DE, Flegal KM et al. Secular trends in cardiovascular disease risk factors according to body mass index in US adults. JAMA 2005; 293: $1868-1874$.

4 Centers for Disease Control and Prevention (CDC. Decline in deaths from heart disease and stroke - United States, 1900-1999. MMWR Morb Mortal Wkly Rep 1999; 48: 649-656.

5 Unal B, Critchley JA, Capewell S. Explaining the decline in coronary heart disease mortality in England and Wales between 1981 and 2000. Circulation 2004; 109: 1101-1107.

6 NHLBI Expert Panel on the Identification, Evaluation and Treatment of Overweight and Obesity in Adults. Clinical guidelines on the identification, evaluation, and treatment of over- 
weight and obesity in adults: executive summary. Available at: http://www.nhlbi.nih.gov/guidelines/obesity/ob_home.htm (accessed December 28, 2005)

7 Amy NK, Aalborg A, Lyons P, Keranen L. Barriers to routine gynecological cancer screening for White and African-American obese women. Int J Obes (London) 2006; 30: 147-155.

8 Wee CC, Phillips RS, McCarthy EP. BMI and cervical cancer screening among white, African-American, and Hispanic women in the United States. Obes Res 2005; 13: 1275-1280.

9 Wee CC, McCarthy EP, Davis RB, Phillips RS. Obesity and breast cancer screening. J Gen Intern Med 2004; 19: 324-331.

10 Wee CC, McCarthy EP, Davis RB, Phillips RS. Screening for cervical and breast cancer: is obesity an unrecognized barrier to preventive care? Ann Intern Med 2000; 132: 697-704.
11 Meisinger C, Heier M, Loewel H. The relationship between body weight and health care among German women. Obes Res 2004; 12: $1473-1480$.

12 Madarnas Y, Sawka CA, Franssen E, Bjarnason GA. Are medical oncologists biased in their treatment of the large woman with breast cancer? Breast Cancer Res Treat 2001; 66: 123-133.

13 Griggs JJ, Sorbero ME, Lyman GH. Undertreatment of obese women receiving breast cancer chemotherapy. Arch Intern Med 2005; 165: 1267-1273.

14 Rosner GL, Hargis JB, Hollis DR, Budman DR, Weiss RB, Henderson IC et al. Relationship between toxicity and obesity in women receiving adjuvant chemotherapy for breast cancer: results from cancer and leukemia group B study 8541. J Clin Oncol 1996; 14: 3000-3008. 